\title{
Sensory Neuron Degeneration in Familial Kugelberg-Welander Disease
}

\author{
Toni R. Winder and Roland N. Auer
}

\begin{abstract}
A 53 year old man developed symptoms of motor neuron disease in childhood. There was a family history of a similar disorder and it was felt to represent a form of Kugelberg-Welander disease. In addition to the motor deficits, sensory abnormalities in his legs were documented during life. Autopsy revealed anterior horn cell loss throughout the length of the spinal cord, with preservation of the phrenic nucleus. The lumbar dorsal root ganglia showed active degeneration of sensory neurons, with nuclear changes exceeding cytoplasmic ones. The fasciculus gracilis showed Wallerian degeneration. The findings provide direct evidence that sensory neurons can degenerate in some forms of motor neuron disease, and that the "demyelination" or "degeneration" of posterior columns sometimes seen in the various forms of motor neuron disease may actually be secondary to cell body disease in the dorsal root ganglia.

RÉSUMÉ: Dégénérescence des neurones sensitifs dans la maladie de Kugelberg-Welander familiale Nous rapportons le cas d'un homme âgé de 53 ans qui a développé des symptômes de maladie du neurone moteur périphérique dans l'enfance. L'histoire familiale faisait état de la présence d'une affection similaire dans sa parenté et il semblait bien qu'il s'agissait d'une forme de la maladie de Kugelberg-Welander. En plus du déficit moteur, des anomalies sensitives ont été objectivées pendant la vie du patient. À l'autopsie, il y avait une perte des cellules de la corne antérieure sur toute la longueur de la moelle épinière, avec préservation du noyau diaphragmatique. Les ganglions spinaux lombaires présentaient une dégénérescence active des neurones sensitifs, les altérations nucléaires étant plus importantes que les modifications cytoplasmiques. Le faisceau gracile présentait une dégénérescence Wallérienne. Ces observations sont une évidence directe que les neurones sensitifs peuvent dégénérer dans certaines formes de maladies du neurone moteur et que la démyélinisation ou la dégénérescence des cordons postérieurs parfois observée dans différentes formes de maladies du neurone moteur peut en fait être secondaire à une maladie du corps cellulaire situé dans les ganglions spinaux.
\end{abstract}

Can. J. Neurol. Sci. 1989; 16:67-70

Sensory neuron involvement in some forms of motor neuron disease has been suggested by clinical studies 1,2 and by comparative morphometric studies of ventral and dorsal spinal roots. ${ }^{3}$ However, direct demonstration of sensory neuron degeneration has been lacking.

We examined the sensory ganglia at autopsy in a case of familial Kugelberg-Welander disease. The results demonstrated active neuronal degeneration, correlating with clinical sensory abnormalities documented during life.

\section{CASE Report}

The patient was 53 years old at the time of death. Although he was not considered to be a floppy infant, he did not begin to walk until 2 years of age, and then in an awkward manner. At age 3-4 years an orthopedic procedure was carried out to correct suspected club feet. During adolescence, there was a slow but progressive deterioration in his motor function. He recalled that he had to be carried up stairs or on long walks as he could not keep up. By age 15, he was confined to a wheelchair because of leg weakness. His arms were affected to a lesser degree. Bulbar symptoms were absent. Progression of his disease was characterized by episodes of deterioration and plateaus when the disease seemed stable.

He first saw a neurologist at age 22 years and was told he had Charcot-Marie-Tooth disease (CMTD). He married and had two neuro- logically normal children now aged 17 and 20 years. They were seen by a neurologist at age 7 and 10 respectively. EMG and nerve conduction studies done because of the father's diagnosis of CMTD were normal.

He was the youngest of four siblings (Figure 1). An older brother died at age 45 of a progressive, wasting neurologic disorder. He had been unable to walk since his early teens, and had been confined to a wheelchair for most of his life. A sister and brother aged 73 and 68 years respectively are alive and well with no neurologic disease. The father died of cardiac causes at 92 years of age, and also had a wasting neurologic condition of some years duration, but no autopsy was performed. The mother died at age 92 of a stroke, without other neurologic disease.

He was admitted to hospital 8 months prior to death with pneumonia. He required intubation and mechanical ventilation. A tracheostomy was performed. The neurologic diagnosis at that time was familial progressive spinal muscular atrophy, autosomal recessive (KugelbergWelander). In addition to the motor deficits, neurologic examination revealed a marked decrease in vibratory sensation in his legs, with a sensory deficit below the $\mathrm{T}_{6}$ level. Motor and sensory nerve conduction studies were normal. With some difficulty he was weaned from the ventilator and eventually was discharged after a 3 month hospital stay.

His final admission was precipitated by further neurologic deterioration and respiratory failure. He again required a tracheostomy and ventilation.

One month after admission, while being moved from his chair into bed, hemorrhage occurred around his tracheostomy site and from his oropharynx. Despite resuscitative attempts, he exsanguinated and died.

From the Departments of Pathology and Clinical Neurosciences, University of Calgary, Calgary

Received September 3, 1987. Accepted in final form August 30, 1988

Reprint requests to: Dr. R. N. Auer, Neuropathology, Health Sciences Center, 3330 Hospital Dr. N.W., Calgary, Alberta, Canada T2N 4N1 


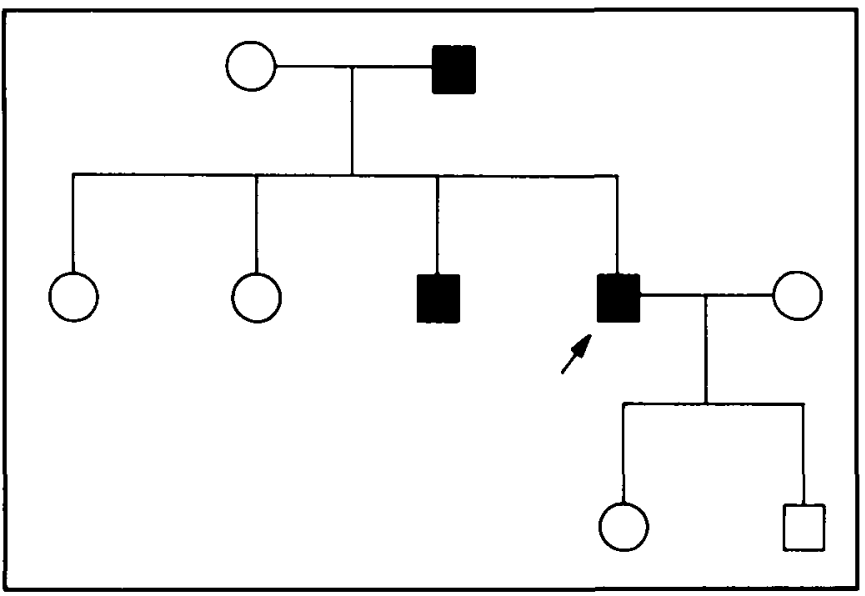

Figure 1 - Family tree demonstrating pattern of affected family members, compatible with either autosomal or sex-linked recessive inheritance.

\section{Autopsy Findings}

At autopsy, the cause of death was a ruptured fistula between the brachiocephalic artery and trachea, with massive pulmonary hemorrhage. The remainder of the general autopsy was normal except for the marked wasting and contracture of his legs, arms and axial skeleton. The brain, spinal cord (including dorsal root ganglia), and skeletal musculature were sampled.

Microscopy of the cerebral cortex, the basal ganglia and diencephalon were normal. Sections through the brainstem revealed only mild gliosis of the hypoglossal nuclei, with minimal neuronal loss.

Multiple levels of spinal cord revealed normal cortico-spinal tracts (Figure 2), but loss of anterior horn cells throughout the spinal cord, sparing the phrenic nucleus (Figure 3). There was pre-necrotic shrinkage of remaining motor neurons. The neurons of Clarke's column were normal.

Prominent degeneration was seen in the fasciculus gracilis (Figure 2). Examination of the lumbo-sacral sensory ganglia revealed that this was related to perikaryal disease. Neuronal cell bodies in the dorsal root ganglia were seen in all stages of degeneration, with nuclear pyknosis preceding cytoplasmic shrinkage. Chromatolysis was not seen. Most cells exhibited at least some degree of nuclear pyknosis, although some normal neurons were found (Figure 4). Extremely shrunken and pyknotic cells, apparently in the final stages of necrosis were also seen. Nodules of Nageotte marked the locations of former cell bodies which had disappeared (Figure 4). Histologic comparison with age-matched dorsal root ganglia taken from the same spinal levels at autopsy, from individuals who had died without neurologic disease, revealed that the frequency and density of these degenerative changes in the dorsal root ganglia of the present case was approximately five times control.

The previous presumptive diagnosis of Charcot-Marie-Tooth disease was not known at the time of autopsy, and peripheral nerve was not specifically taken, but intramuscular nerves and spinal roots were available for examination.

The dorsal and ventral nerve roots both showed axonal loss (Figure 5). The skeletal musculature showed individual muscle fiber atrophy and grouped fiber atrophy. Intramuscular nerves showed some depletion of axons and occasional axonal swellings (Figure 6).

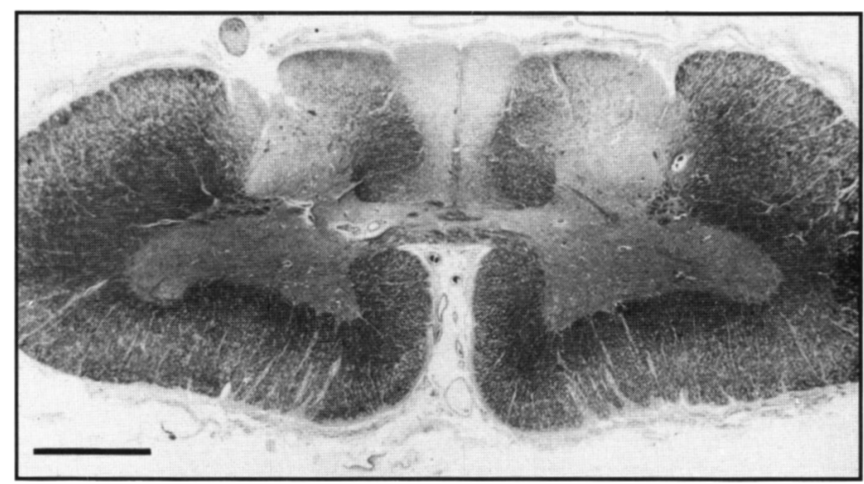

Figure 2-Cervical spinal cord, showing degeneration of the fasciculus gracilis, but not fasciculus cuneatus - The cortico-spinal tracts are normal. $H \& E / L F B$, bar $=2 \mathrm{~mm}$

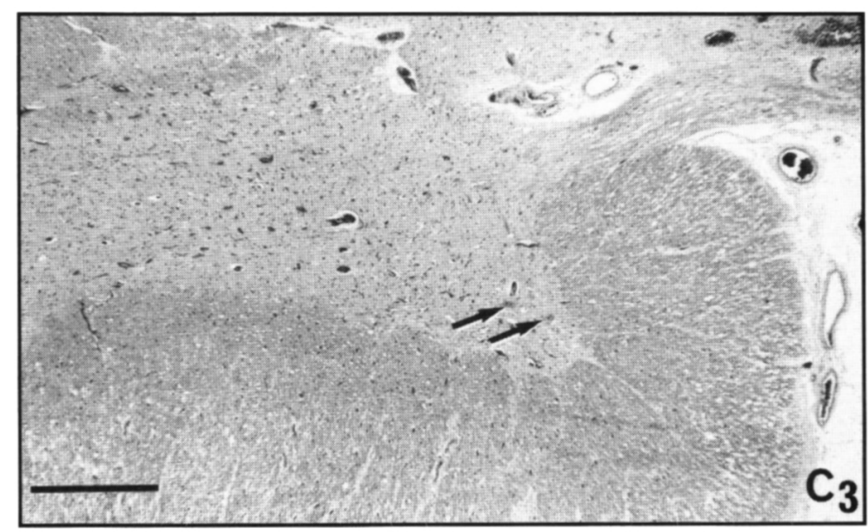

Figure 3-Gliosis and total loss of anterior horn cells are seen, sparing only motor neurons of the phrenic nucleus (arrows) at this spinal cord level. C3 level, cervical cord. $H \& E$, bar $=500 \mu \mathrm{m}$.

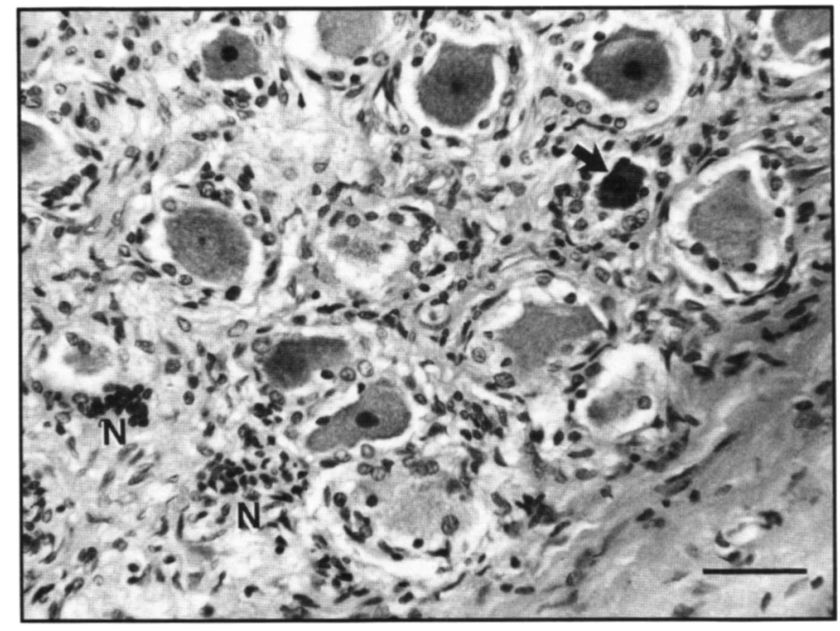

Figure 4 - Lumbar dorsal root ganglia under high magnification reveal evidence of neuronal degeneration. A single healthy appearing neuron is seen in the center left. but the remainder of the neuronal population shows nuclear pyknosis of varying degrees. In addition, advanced cellular lesions are seen, marked by severe cytoplasmic shrinkage and hyperchromasia (arrow) heralding necrosis. Nodules of Nageotte $(N)$, marking the location of former neurons, are seen. Age matched controls showed only a minor degree of such changes. $H \& E$, bar $=100 \mu \mathrm{m}$. 

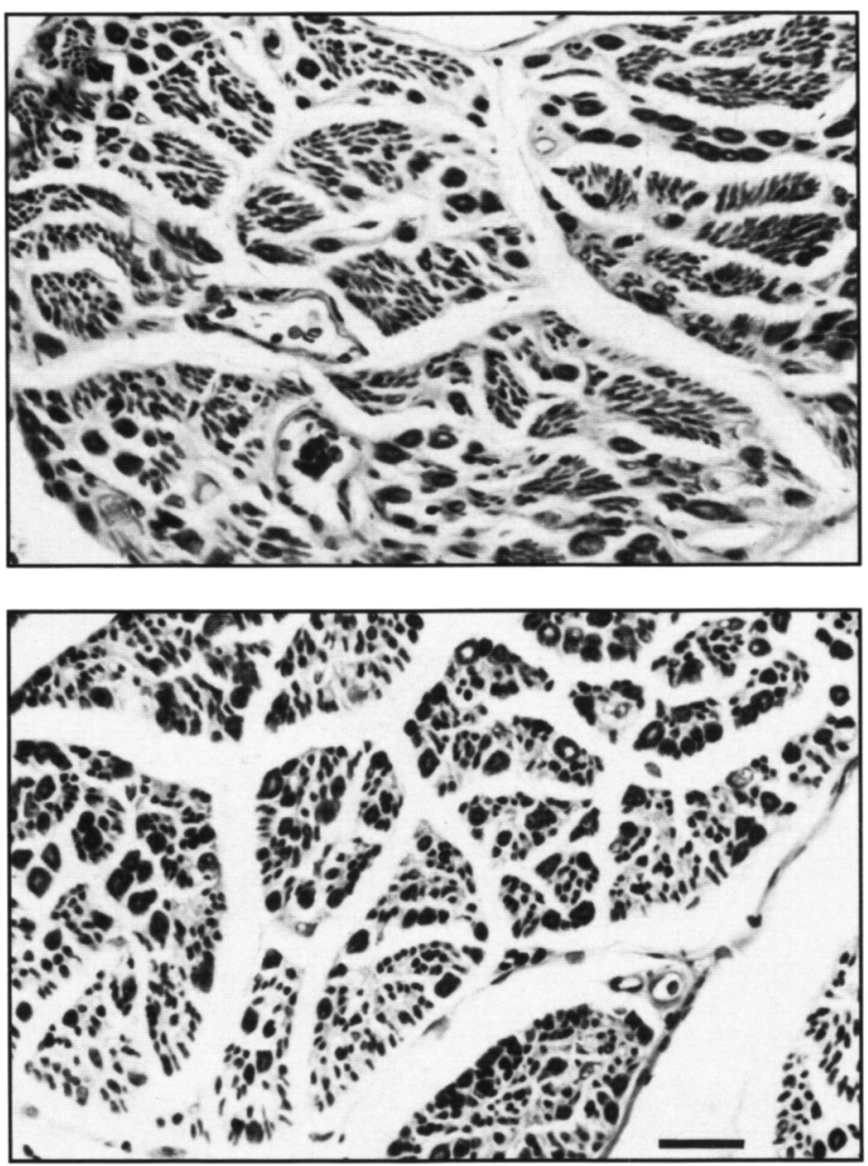

Figure 5 - Nerve roots from lumbar spinal cord. Dorsal roots (upper) and ventral roots (lower) show only mild axonal loss. LFB, bar = $100 \mu \mathrm{m}$

\section{Discussion}

The onset of disease in childhood and the indolent clinical course place the present case in the spectrum between WerdnigHoffmann disease of infancy, and the classic adult form of motor neuron disease - amyotrophic lateral sclerosis, (ALS) and it is most appropriately considered as a form of KugelbergWelander disease. The case demonstrated the hallmark findings of motor neuron disease; severe anterior horn cell loss and gliosis. Sparing of the phrenic nucleus was seen, as reported in amyotrophic lateral sclerosis ${ }^{4}$ and Werdnig-Hoffmann disease. ${ }^{5}$

A clinical diagnosis of Charcot-Marie-Tooth disease (CMTD) was made when the patient was in his early twenties, but subsequent nerve conduction studies later in the disease process were normal, weighing heavily against that diagnosis. The diagnosis of the rarer "neuronal form" of Charcot-Marie-Tooth disease ${ }^{6}$ could be applied in this case, in view of the motor and sensory neuron degeneration which can be seen in that disorder, as well as axonal spheroids in intramuscular nerves. ${ }^{7}$ However, patients with the neuronal form of CMTD have shown a relatively benign clinical course, without progressing to respiratory insufficiency requiring intubation. ${ }^{7}$ The nosologic distinction between "neuronal forms" of CMTD and forms of motor neuron disease involving sensory neurons is tenuous at best.

A familial form of motor neuron disease - amyotrophic lateral sclerosis has been described by Engel et al. ${ }^{8}$ The disease
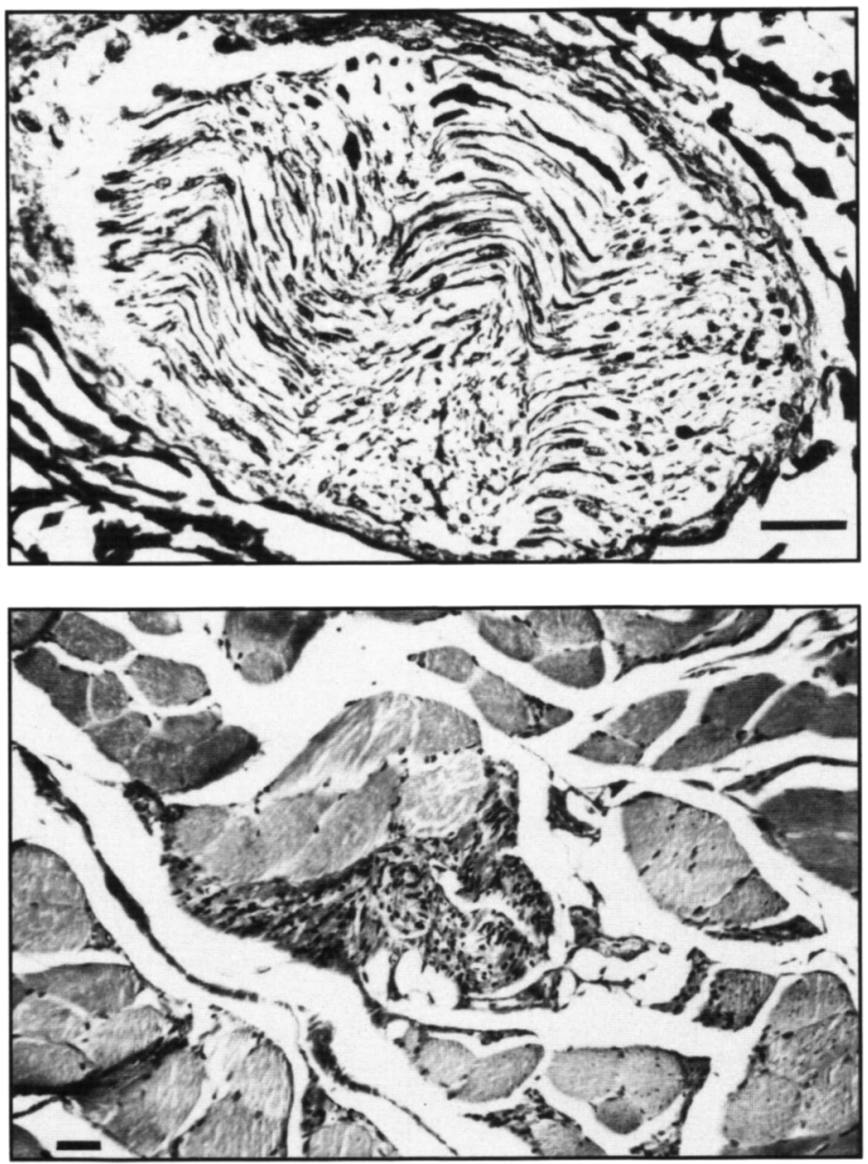

Figure 6-Intramuscular nerves show axonal spheroids (upper). Bar $=50 \mu \mathrm{m}$. Prominent neurogenic atrophy is seen in the leg muscles (lower). Bielschowsky, bar $=100 \mu \mathrm{m}$.

progressed over 2-3 years in several members of two families. At autopsy, there was degeneration of the fasciculus gracilis but the dorsal root ganglia were not examined.

Sensory abnormatities have been reported in ALS, noted in slightly over $10 \%$ of cases. ${ }^{2}$ However, this figure may be low. A report of four cases ${ }^{1}$ described sensory symptoms in the feet and legs. At autopsy, 2 had posterior column degeneration (fasciculus gracilis) and one had dorsal root ganglia involvement. Sensory neuron degeneration in motor neuron disease was strongly suggested by a morphometric study of dorsal and ventral roots. ${ }^{3}$

Familial ALS has been suggested to have more common involvement of sensory tracts than sporadic ALS, perhaps as high as $70 \%$. Recently Radtke et al $^{9}$ have shown sensory evoked potential abnormalities in 7 of 16 patients with ALS, corroborating previous observations. There is evidence in classical motor neuron disease for involvement of the neurons of Clarke's column in addition to sensory neurons - see Tandan and Bradley for review. ${ }^{4}$

In Werdnig-Hoffmann disease, chromatolysis and neuronal degeneration have been reported in the dorsal root ganglia 10.11 as well as the thalamus, dentate nucleus, optic nerve, Clarke's column, and lateral geniculate body, ${ }^{10-12}$ suggesting that Werdnig-Hoffmann disease might best be classified as a neuronal system degeneration rather than a pure motor neuron disorder. Although sensory neuron involvement is possibly a con- 
stant feature of Werdnig-Hoffmann disease, ${ }^{11}$ clinical sensory abnormalities are not a regular feature. 13

Familial cases have been more common than sporadic cases in previous reports of Kugelberg-Welander motor neuron disease. ${ }^{14.15}$ Although sensory changes are not usually reported, demyelination in the dorsal columns has been seen.

The present case is the first report of Kugelberg-Welander disease with documented sensory changes during life, long tract changes in the posterior columns, and autopsy-proven active degeneration of dorsal root ganglia neurons. The importance of neuropathologic examination of dorsal root ganglia in motor neuron disease is underscored. Degeneration of the posterior columns in motor neuron disease may not be a primary process in the spinal cord, but rather represent secondary Wallerian degeneration due to cell death in the dorsal root ganglia.

\section{ACKNOWLEDGEMENT}

The authors wish to thank Ms. E. Tingle for typing the manuscript.

\section{REFERENCES}

1. Luthy F, Martin F. Observation de case de sclérose latérale amyotrophique avec considération particulière sur la participation sensitive. Schweiz Med Wchnschr 1947; 25: 694-697.

2. Lawyer T, Netsky MD. ALS: a clinicoanatomic study of 53 cases. Arch Neurol Psychiat (Chic) 1953; 69: 171-192.

3. Kawamura Y, Dyck PJ, Shimono M, et al. Morphometric comparison of the vulnerability of peripheral motor and sensory neurons in amyotrophic lateral sclerosis. J Neuropathol Exp Neurol 1981; 40: 667-675.
4. Tandan R, Bradley WG. Amyotrophic lateral sclerosis: part 1. Clinical features, pathology, and ethical issues in management. Ann Neurol 1985; 18: 271-280.

5. Kuzuhara S, Chou SM. Preservation of the phrenic motoneurons in Werdnig-Hoffmann disease. Ann Neurol 1981; 9: 506-510.

6. Dyck PJ, Lambert EH. Lower motor and primary sensory neuron diseases with peroneal muscular atrophy. II. Neurologic, genetic, and electrophysiologic findings in various neuronal degenerations. Arch Neurol 1968; 18: 619-625.

7. Hughes JT, Brownell B. Pathology of peroneal muscular atrophy (Charcot-Marie-Tooth disease). J Neurol Neurosurg Psychiatry 1972; 35: 648-657.

8. Engel WK, Kurland LT, Klatzo I. An inherited disease similar to ALS with a pattern of posterior column involvement. An intermediate form? Brain 1959; 82: 203-219.

9. Radtke RA, Erwin A, Erwin CW. Abnormal sensory evoked potentials in ALS. Neurology 1986; 36: 796-801.

10. Towfighi J, Young RSK, Ward RM. Is Werdnig-Hoffmann disease a pure lower motor neuron disorder? Acta Neuropathol (Berl) 1985; 65: 270-280.

11. Carpenter S, Karpati G, Rothman S, et al. Pathological involvement of primary sensory neurons in Werdnig-Hoffmann disease. Acta Neuropathol (Berl) 1978; 42: 91-97.

12. Peress NS, Stermann AB, Miller R, et al. "Chromatolytic" neurons in lateral geniculate body in Werdnig-Hoffmann disease. Clin Neuropathol 1986; 5: 69-72.

13. Shishikura K, Hara M, Sasaki Y, et al. A neuropathologic study of Werdnig-Hoffmann disease with special reference to the thalamus and posterior roots. Acta Neuropathol (Berl) 1983; 60: 99 106.

14. Kugelberg E. Chronic proximal (pseudomyopathic) spinal muscular atrophy. In: Vinken PJ, Bruyn GW, eds. Handbook of clinical neurology. New York: North-Holland Publishing Co. 1975: 6780

15. Paulson GW, Liss L, Sweeney PJ. Late onset spinal muscle atrophy - a sex linked variant of Kugelberg-Welander. Acta Neurol Scand 1980; 61: 49-55. 